\title{
Row-Column Addressed 2-D CMUT Arrays with Integrated Apodization
}

Christiansen, Thomas Lehrmann; Rasmussen, Morten Fischer; Jensen, Jørgen Arendt; Thomsen, Erik Vilain

\section{Published in:}

Proceedings of 2014 IEEE International Ultrasonics Symposium

Link to article, DOI:

10.1109/ULTSYM.2014.0147

Publication date:

2014

Document Version

Early version, also known as pre-print

Link back to DTU Orbit

Citation $(A P A)$ :

Christiansen, T. L., Rasmussen, M. F., Jensen, J. A., \& Thomsen, E. V. (2014). Row-Column Addressed 2-D CMUT Arrays with Integrated Apodization. In Proceedings of 2014 IEEE International Ultrasonics Symposium (pp. 600-603). IEEE. https://doi.org/10.1109/ULTSYM.2014.0147

\section{General rights}

Copyright and moral rights for the publications made accessible in the public portal are retained by the authors and/or other copyright owners and it is a condition of accessing publications that users recognise and abide by the legal requirements associated with these rights.

- Users may download and print one copy of any publication from the public portal for the purpose of private study or research.

- You may not further distribute the material or use it for any profit-making activity or commercial gain

- You may freely distribute the URL identifying the publication in the public portal 
Paper presented at the 2014 IEEE International Ultrasonics Symposium:

\section{Row-Column Addressed 2-D CMUT Arrays with Integrated Apodization}

Thomas Lehrmann Christiansen, Morten Fischer Rasmussen, Jørgen Arendt Jensen and Erik Vilain Thomsen

Center for Fast Ultrasound Imaging, Biomedical Engineering Group,

Department of Electrical Engineering

Ørsteds Plads Building 349,

Technical University of Denmark, 2800 Kgs. Lyngby, Denmark. 


\title{
Row-Column Addressed 2-D CMUT Arrays with Integrated Apodization
}

\author{
Thomas Lehrmann Christiansen*, Morten Fischer Rasmussen ${ }^{\dagger}$, Jørgen Arendt Jensen ${ }^{\dagger}$ and Erik Vilain Thomsen* \\ *Department of Micro- and Nanotechnology, Technical University of Denmark, DK-2800 Kgs. Lyngby, Denmark \\ ${ }^{\dagger}$ Center for Fast Ultrasound Imaging, Department of Electrical Engineering, \\ Technical University of Denmark, DK-2800 Kgs. Lyngby, Denmark
}

\begin{abstract}
Experimental results from row-column addressed capacitive micromachined ultrasonic transducers (CMUTs) with integrated apodization are presented. The apodization is applied by varying the density of CMUT cells in the array with the objective of damping the edge waves originating from the element ends. Two row-column addressed $32+32$ CMUT arrays are produced using a wafer-bonding technique, one with and one without integrated apodization. Hydrophone measurements of the emitted pressure field from the array with integrated apodization show a reduction in edge wave energy of $8.4 \mathrm{~dB}(85 \%)$ compared to the array without integrated apodization. Field II simulations yield a corresponding reduction of $13.0 \mathrm{~dB}(95 \%)$. The simulations are able to replicate the measured pressure field, proving the predictability of the technique.
\end{abstract}

\section{INTRODUCTION}

Row-column addressed arrays for ultrasonic imaging have recently attracted some attention, as they offer volumetric imaging with a greatly reduced number of connections to the array compared to fully wired 2-D matrix probes [1]-[4]. Despite this advantage, such arrays have an inherent drawback: the long elements produce edge waves originating from the abrupt truncation at the element ends. These edge waves generate artefacts in the image in the form of ghost echoes [1], [5]. Due to the row-column addressing scheme, no electronic control is available along the length of the elements. As a consequence, this rules out the option of applying electronic apodization to remove the effect of the truncation. A solution is to integrate the apodization in the transducer array itself, as suggested in recent studies [1], [5]. Several embodiments of the integrated apodization have been suggested, such as attenuating layers [1], variation in the active element area, and bias control of capacitive micromachined ultrasonic transducers (CMUTs) to alter the emitted/received energy [6].

The objective of this paper is to experimentally demonstrate the effect of an integrated apodization based on variation of the effective area through measurements of the emitted pressure field. Experimental results are presented from two versions of a $32+32$ row-column addressed CMUT array; one without integrated apodization and one with integrated apodization. Simulations in Field II [7], [8] are carried out to compare the measured pressure field with the expected, thereby demonstrating the predictability of the technique.

\section{TRANSDUCER Design}

In this study, two $32+32$ row-column addressed CMUT arrays are produced; one without integrated apodization and

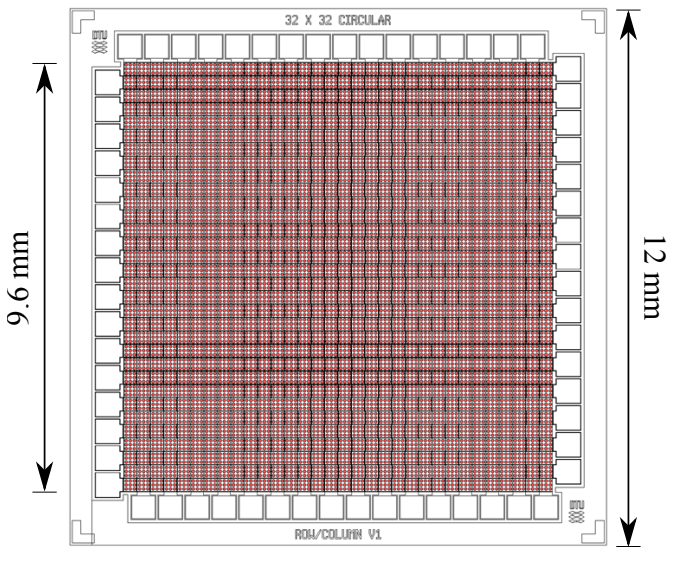

(a)

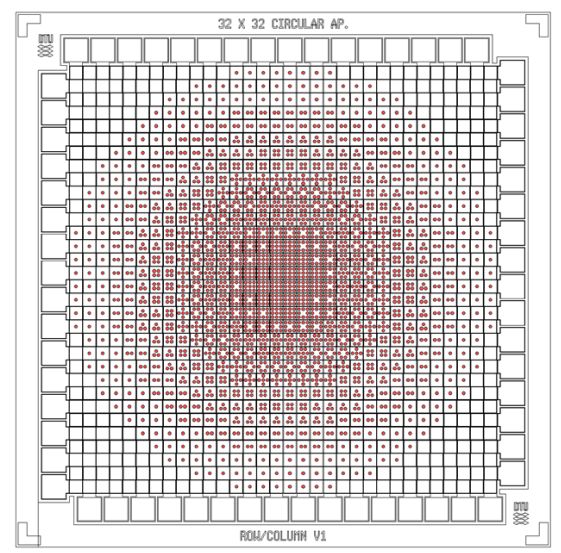

(b)

Figure 1. Mask layout of the row-column addressed $32+32$ CMUT transducers without integrated apodization (a) and with integrated apodization (b). The red circles indicate the individual CMUT cells, which are densely packed in the non-apodized configuration, while the number of cells follows a circular symmetric Hann function in the apodized layout.

one with integrated apodization. The mask layout of the two transducer arrays are depicted in Fig. 1. The two transducers both have a total size of $12 \mathrm{~mm} \times 12 \mathrm{~mm}$, a pitch of $300 \mu \mathrm{m}$, an element kerf of $12 \mu \mathrm{m}$, and a total of 32 row elements and 32 column elements. The aperture size is consequently $9.6 \mathrm{~mm} \times 9.6 \mathrm{~mm}$. In the array with no integrated apodization (Fig. 1a), circular CMUT cells are densely distributed over the array, with 3 cells along the width of the elements and 96 cells along their length. The individual cells have a diameter of 
a)

b)

c)

d)

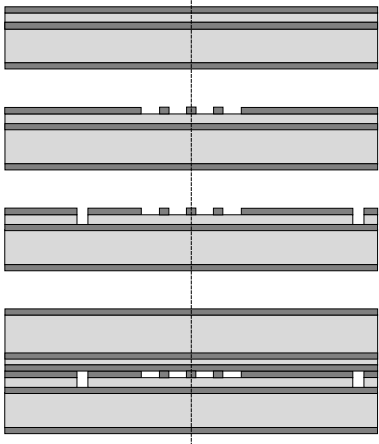

h)

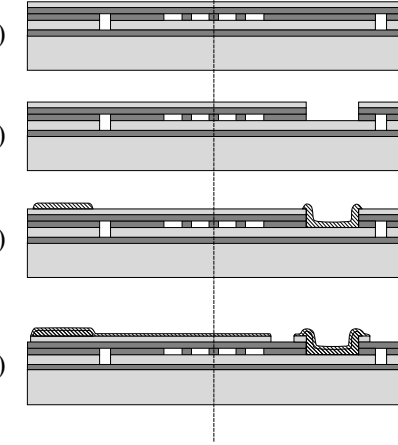

$\mathrm{SiO}_{2}$

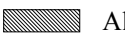

Figure 2. Process flow of the cleanroom fabrication. The line separates the layer composition comprising the top electrodes (to the left of the line) and the bottom electrodes (to the right of the line). The steps are: a) oxidation, b) cavity etch, c) bottom electrode etch, d) wafer bonding, e) handle etch, f) etch access to bottom electrodes, g) deposit and etch wire-bonding pads, and h) deposit and etch top electrodes. A total of five lithography masks are used (in steps b, c, f, g, and h).

$72 \mu \mathrm{m}$, a plate thickness of $2 \mu \mathrm{m}$, and a vacuum gap height and insulation oxide thickness of each $195 \mathrm{~nm}$. Each section of the array, where a row and a column intersects, can accommodate a maximum of 9 CMUT cells. For the array with integrated apodization (Fig. 1b), the number of cells in this square section is varied according to a circularly symmetric Hann function. This effectively alters the active area and consequently the intensity of the emitted/received signal, gradually decreasing it towards the edges of the array to suppress the edge waves.

\section{TRANSDUCER FABRICATION}

The arrays were fabricated using cleanroom processing techniques, partly based on previous works described in the literature [9], [10]. The individual process steps are shown in Fig. 2.

The fabrication process utilized two (001) silicon-oninsulator (SOI) wafers, both having a $525 \mu \mathrm{m}$ thick handle layer with high resistivity $(1-10 \Omega \mathrm{cm})$, a $1 \mu \mathrm{m}$ thick buried oxide layer, and a low resistivity $(0.01-0.001 \Omega \mathrm{cm})$ device layer. The device layer on the first SOI wafer was $20 \mu \mathrm{m}$ thick and was used to create the bottom electrodes (rows). The second SOI wafer had a $1.9 \mu \mathrm{m}$ thick device layer, which was used for the top electrodes (columns) of the array. These top electrodes also constituted the flexible plate of the CMUTs.

Both SOI wafers were dry oxidized at $1100{ }^{\circ} \mathrm{C}$ for 2 hours and 30 minutes to grow a $195 \mathrm{~nm}$ thick layer of oxide (Fig. 2a). The CMUT cavities were then defined in the $20 \mu \mathrm{m}$ SOI wafer using UV lithography and etched using reactive ion etching (RIE), see Fig. 2b. After stripping the photoresist, a second lithography step was used to define the bottom electrodes as shown in Fig. 2c. Two consecutive RIE etches were used to selectively etch first the oxide layer and subsequently the underlying silicon device layer. After stripping the photoresist, the fabrication of the bottom electrodes and the substrate supporting the array was complete.

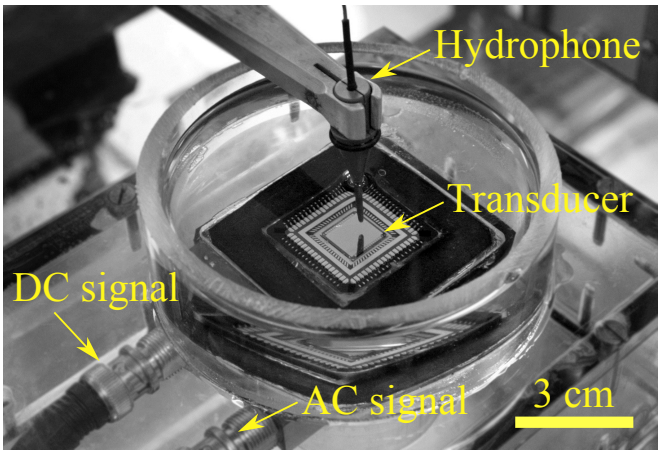

Figure 3. Picture of the experimental setup used to measure the emitted pressure field. The transducer is mounted and wire-bonded on a chip carrier, which is inserted into a chip socket. The transducer array is submerged in rapeseed oil, and a single $\mathrm{AC}+\mathrm{DC}$ signal is supplied to all the column channels of the array, while the row are grounded.

Both SOI wafers were then cleaned using a standard RCA cleaning procedure [11] and bonded together in vacuum (0.01 mbar) using fusion bonding and a subsequent annealing step $\left(70 \mathrm{~min}\right.$ at $\left.1100^{\circ} \mathrm{C}\right)$, see Fig. 2 d. The oxide layer covering the back side of both wafers was removed in buffered hydrofluoric acid (BHF), after which the handle layer and buried oxide layer of the top SOI wafer was etched using both RIE and BHF, respectively, as shown in Fig. 2e.

A third lithography step followed by selective RIE in first the silicon layer and subsequently the oxide layer was used to define openings to the bottom electrodes, see Fig. 2f. The thin device layer is partly transparent in the visible spectrum, and alignment to the bottom wafer alignment marks could therefore be performed, thereby omitting the need for alignment during the wafer bonding step.

Fig. $2 \mathrm{~g}$ shows the wire-bonding pads, which were made by depositing a $800 \mathrm{~nm}$ aluminium layer on the entire wafer using electron beam evaporation and structured in a resist masked selective aluminium etch in $\mathrm{H}_{2} \mathrm{O}: \mathrm{H}_{3} \mathrm{PO}_{4}(1: 2)$ at $50{ }^{\circ} \mathrm{C}$. The top electrodes, or columns, were then finally defined by a step similar to the previous, but this time with a $200 \mathrm{~nm}$ aluminium deposition. Before removing the photoresist, the exposed silicon layer was etched using RIE to isolate the individual top electrodes, thereby concluding the fabrication process (Fig. 2h).

\section{Measurement and Simulation Setup}

The acoustic field of the two CMUT arrays were measured with a MH28-5 needle hydrophone (Force Technology, Denmark) and a DSO5012A oscilloscope (Agilent Technologies, CA, USA). The measurement setup is shown in Fig. 3. For spatial mapping of the transmit fields, the hydrophone was mounted on the positioner of the intensity measurement system AIMS-3 (Onda Corporation, CA, USA). The hydrophone was positioned $5.3 \mathrm{~mm}$ from the array and scanned over the center of each array in lateral steps of $0.1 \mathrm{~mm}$. The transducers were actuated using a 8116A pulse/function generator (HewlettPackard Company, CA, USA) with a $15 \mathrm{Vpp} 2$-cycle $3 \mathrm{MHz}$ pulse through a custom made class $\mathrm{B}$ amplifier with a 
bandwidth of $8 \mathrm{MHz}$. The DC bias was $40 \mathrm{~V}$ (pull-in: $52 \mathrm{~V}$ ). All row elements, respectively column elements, were electrically shorted to allow simultaneous actuation of the whole array All measurements were carried out in rapeseed oil (speed of sound: $1476 \mathrm{~m} / \mathrm{s}$ ) to ensure electrical insulation of the prototype transducers.

In this work, Field II [7], [8] was used for all simulations. Field II was set up to use lines to describe the apertures with each element of the array being divided into square mathematical elements with a side length of $\lambda / 4$. In the simulation, the square intersection of each row- and column element, each consisting of four mathematical elements, were given an apodization value of $\left\{0, \frac{1}{9}, \frac{2}{9}, \frac{1}{3}, \frac{4}{9}, \frac{5}{9}, \frac{2}{3}, \frac{7}{9}, \frac{8}{9}, 1\right\}$ dependent on whether there were $0,1,2,3,4,5,6,7,8$, or 9 CMUT cells in the real array within this region. The emission pulse was a $3 \mathrm{MHz} 2$-cycle Hann weighted pulse.

\section{RESULTS}

The measured and simulated emitted fields generated by the two arrays are shown in Fig. 4. The result for the array without integrated apodization is shown in Fig. 4a and Fig. 4c (simulation and measurement, respectively), while the result for the array with integrated apodization is shown in Fig. $4 \mathrm{~b}$ and Fig. 4d. The main wave arrives after $3.6 \mu$ s, corresponding to a distance of $5.3 \mathrm{~mm}$. In addition to this, a spherical wave is emitted from the edges of the array. The arrival time of the wave front is the distance travelled divided by the speed of sound. The arrival time of the edge wave at the position of the hydrophone is then

$$
t_{\text {edge }}=\sqrt{d^{2}+x^{2}} / c
$$

where $d$ is the perpendicular distance from the point being measured and the transducer surface, $x$ is the lateral distance of the point being measured from the edge of the array, and $c$ is the speed of sound. The predicted arrival time of an edge wave originating from the array aperture edge at $-4.8 \mathrm{~mm}$ has been plotted with a dashed line in both the simulated and measured fields for the array without integrated apodization in Fig. $4 \mathrm{a}$ and Fig. $4 \mathrm{~b}$, respectively. It is seen that the edge wave is accurately predicted, thereby confirming its origin.

For the array with integrated apodization (Fig. 4b and Fig. 4d), the two edge waves are seen to be significantly damped. The damping in terms of edge wave energy can be quantified by summing the squared pressure values along the curve given by (1) for both arrays. This yields a reduction of edge wave energy of $13.0 \mathrm{~dB}(95 \%)$ for the simulation and $8.4 \mathrm{~dB}(85 \%)$ for the measurement. The deviance between the simulation and measurement may be contributed to the transducer ringing present in the measurements due to the lack of a backing material. This will add to the calculated edge wave energy in both cases and thereby reduce the energy ratio.

In Fig. 5a and Fig. 5b, the amplitude of the measured and simulated pressure field is shown for the two arrays. The amplitude is extracted at the arrival of the main wave at time $3.6 \mu \mathrm{s}$, and it thereby corresponds to a horizontal cross-section of the plots in Fig. 4. The profiles of the simulated and measured amplitudes are seen to be comparable for both of the arrays The correspondence is especially relevant for the array with integrated apodization, since it demonstrates that the emitted field, and thereby the apodization, can be accurately predicted.

\section{CONCLUSIONS}

This paper demonstrated the effect of an integrated apodization in row-column addressed CMUTs. The apodization was applied by varying the density of CMUT cells in the array with the objective of damping the edge waves originating from the element ends, thereby mitigating the problem of ghost echoes in images produced by such arrays. Two row-column addressed $32+32$ CMUT arrays were fabricated, one with and one without integrated apodization. Measurements of the emitted pressure field from the array with integrated apodization showed a reduction in edge wave energy of $8.4 \mathrm{~dB}$ (85\%) compared to the array without integrated apodization. Simulations in Field II yielded a corresponding reduction of $13.0 \mathrm{~dB}(95 \%)$. The simulations were able to replicate the measured pressure field, proving the predictability of the technique.

\section{ACKNOWLEDGMENT}

This work was financially supported by the Danish National Advanced Technology Foundation (024-2008-3 and 82-20124). The authors would like to thank Jens Christian Jensen for producing the mechanical fixtures, and René Gadkjær for assistance with the electronics.

\section{REFERENCES}

[1] C. E. M. Démoré, A. Joyce, K. Wall, and G. Lockwood, "Real-time volume imaging using a crossed electrode array," IEEE Trans. Ultrason., Ferroelec., Freq. Contr., vol. 56, no. 6, pp. 1252-1261, 2009.

[2] C. H. Seo and J. T. Yen, "A 256 x 256 2-D array transducer with rowcolumn addressing for 3-D rectilinear imaging," IEEE Trans. Ultrason. Ferroelec., Freq. Contr., vol. 56, no. 4, pp. 837-847, apr 2009.

[3] A. S. Logan, L. L. P. Wong, A. I. H. Chen, and J. T. W. Yeow, "A 32 x 32 element row-column addressed capacitive micromachined ultrasonic transducer,' IEEE Trans. Ultrason., Ferroelec., Freq. Contr., vol. 58, no. 6, pp. 1266-1271, jun 2011.

[4] A. Sampaleanu, P. Zhang, A. Kshirsagar, W. Moussa, and R. Zemp, "Toporthogonal-to-bottom-electrode (TOBE) CMUT arrays for 3-D ultrasound imaging." IEEE Trans. Ultrason., Ferroelec., Freq. Contr., vol. 61, no. 2, pp. 266-276, 2014

[5] M. F. Rasmussen and J. A. Jensen, "3-D ultrasound imaging performance of a row-column addressed 2-D array transducer: A measurement study," in Proc. IEEE Ultrason. Symp., july 2013, pp. 1460-1463.

[6] T. L. Christiansen, M. F. Rasmussen, E. V. Thomsen, and J. A. Jensen, "Ultrasound imaging transducer array with integrated apodization," International Patent PCT/IB2013/002 838, December 19, 2013.

[7] J. A. Jensen and N. B. Svendsen, "Calculation of Pressure Fields from Arbitrarily Shaped, Apodized, and Excited Ultrasound Transducers," IEEE Trans. Ultrason., Ferroelec., Freq. Contr., vol. 39, pp. 262-267, 1992.

[8] J. A. Jensen, "Field: A program for simulating ultrasound systems," Med. Biol. Eng. Comp., vol. 10th Nordic-Baltic Conference on Biomedical Imaging, Vol. 4, Supplement 1, Part 1, pp. 351-353, 1996.

[9] Y. Huang, A. S. Ergun, E. Hæggström, M. H. Badi, and B. T. KhuriYakub, "Fabricating capacitive micromachined ultrasonic transducers with wafer-bonding technology," J. Microelectromech. S., vol. 12, no. 2, pp. 128-137, 2003.

[10] P. Zhang, G. Fitzpatrick, T. Harrison, W. A. Moussa, and R. J Zemp, "Double-SOI wafer-bonded CMUTs with improved electrical safety and minimal roughness of dielectric and electrode surfaces," $J$. Microelectromech. Syst., vol. 21, no. 3, pp. 668-680, 2012.

[11] W. Kern, "The evolution of silicon wafer cleaning technology," $J$. Electrochem. Soc., vol. 137, no. 6, pp. 1887-1892, 1990. 


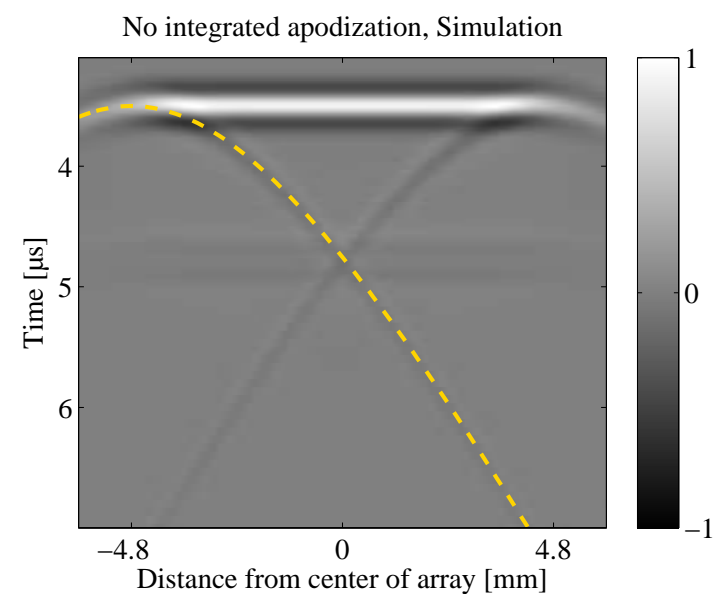

(a)

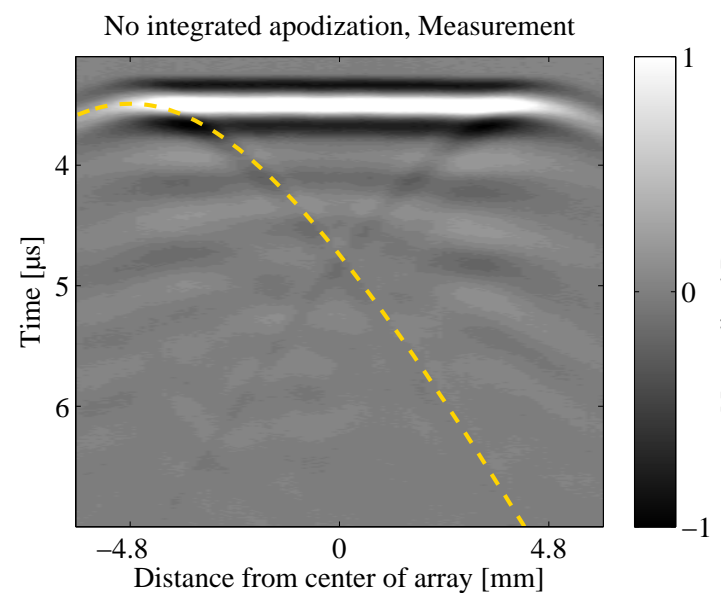

(c)

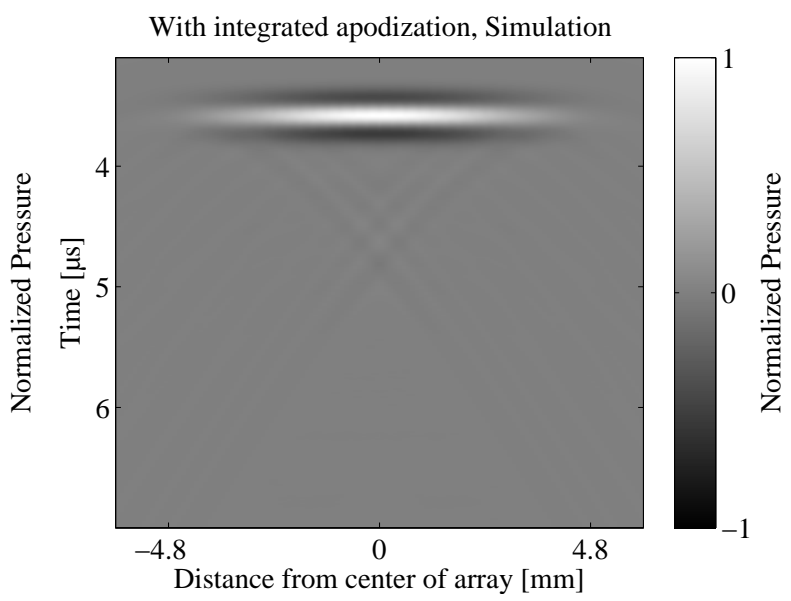

(b)

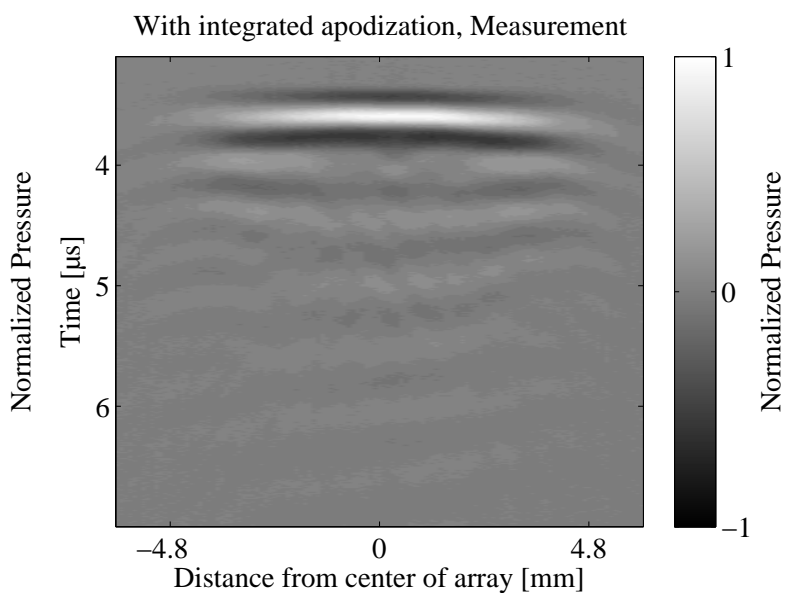

(d)

Figure 4. Simulated ( $a$ and $b$ ) and measured ( $c$ and d) pressure field along a line through the center of the array at a depth of $5.3 \mathrm{~mm}$. a and $\mathrm{c}$ show the result for the array without integrated apodization, and $\mathrm{b}$ and $\mathrm{d}$ show the result with integrated Hann apodization. The pressure has been normalized to the maximum pressure of the measurement with no integrated apodization. The extend of the array aperture (from $-4.8 \mathrm{~mm}$ to $4.8 \mathrm{~mm}$ ) is marked. Two edge waves are clearly visible for the non-apodized array, and the dashed line show the analytically calculated expected arrival time of the edge wave originating at $-4.8 \mathrm{~mm}$. The ripples in the experimental results are due to transducer ringing, and these are therefore not reproduced in the simulations.

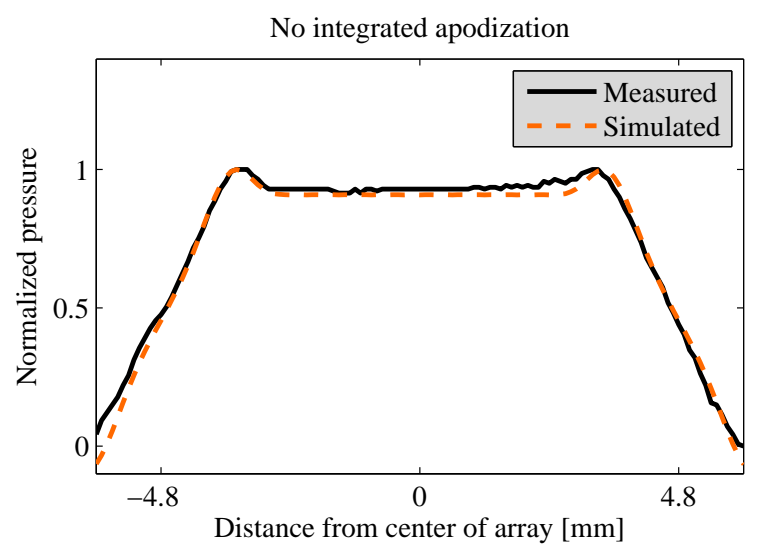

(a)

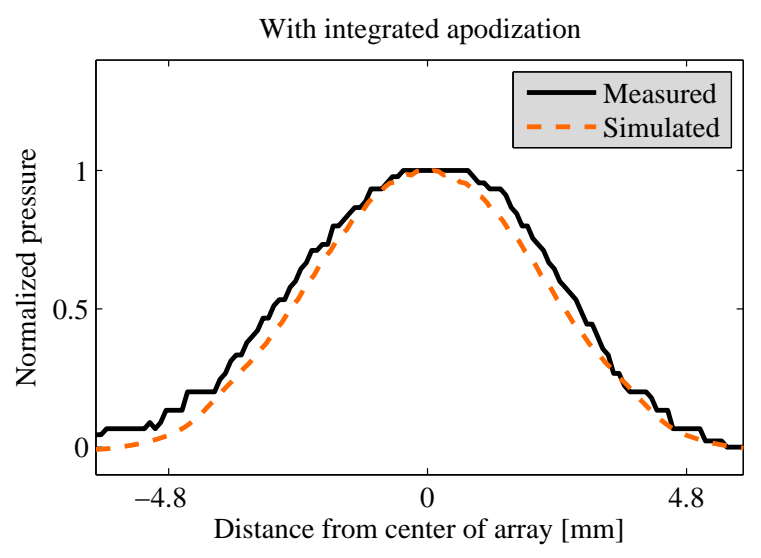

(b)

Figure 5. Measured and simulated pressure at a distance of $5.3 \mathrm{~mm}$ from the transducer surface. The pressure is measured along a line through the center of the array. The extend of the array aperture (from $-4.8 \mathrm{~mm}$ to $4.8 \mathrm{~mm}$ ) is marked. The pressure has been normalized to the maximum pressure to allow comparison of the profile of the emitted field over the array. 